\title{
Antibiotic Susceptibility Pattern of Methicillin Resistant Staphylococcus aureus from Septicemia Suspected Children in Tertiary Hospital in Hosur, South India
}

\author{
M. Saravanan ${ }^{1, *}$, Anima Nanda ${ }^{2}$, Tewelde Tesfaye $^{1}$ \\ ${ }^{1}$ Department of Medical Microbiology and Immunology, Institute of Biomedical Sciences, College of Health Sciences, Mekelle \\ University, Mekelle, Ethiopia. \\ ${ }^{2}$ Department of Biomedical Engineering, Sathyabama University, Jeppiaar Nagar, Tamilnadu, India \\ *Corresponding author: bioinfosaran@gmail.com
}

Received January 02, 2013; Revised February 06, 2013; Accepted April 03, 2013

\begin{abstract}
Septicemia is an important cause of morbidity and mortality among children in India. A wide variety of bacterial and fungal pathogen can cause septicemia. The objective of the present study is to determine the antibiotic susceptibility pattern of methicillin resistance Staphylococcus aureus from septicemia suspected children. A crosssectional study was undertaken from June, 2011 to August, 2012. A total of 300 children were screened. Study subjects were conveniently selected until the required sample size is full filled; blood samples were collected, transported and microbiologically processed using standard procedures; and data was cleaned and entered into a computer and statistical analysis was performed using SPSS for windows version 16. 88 (29.3\%) were culture positive. S. aureus was the prominent isolate 26 (29.54\%). Of which 8(30.76\% were methicillin resistant (MRSA). The present study reveals MRSA isolates were resistant to mostly all antibiotics and were sensitive to oxacillin and vancomycin.
\end{abstract}

Keywords: MRSA, antibiotic, susceptibility pattern, septicemia, children

\section{Introduction}

Staphylococcus aureus is a frequent cause of infections in children, ranging from skin and soft tissue to invasive life-threatening infection [1]. It is an important cause of community and hospital infections [2]. Communityassociated MRSA (CA-MRSA) infection in children is an increasing public health problem [3]. These CA-MRSA strains cause serious skin and soft tissue infections, necrotizing pneumonia, and sepsis in healthy children [4].

Methicillin Resistant Staphylococcus aureus (MRSA) has been the most commonly recognized multidrugresistant pathogen in the universe and the emergence of MRSA strains found in increasing number of infections and often multi drug resistant in nature now pose serious therapeutic problems to clinicians [5,6]. MRSA strains are usually resistant to several groups of broad spectrum antibiotics that are used on a large scale in the hospital. The mechanism of increased spreading under antibiotic pressure may have contributed to the worldwide increases in the prevalence of MRSA in hospitals [7,8]. The most remarkable feature of $S$. aureus is its ability to acquire resistance to antibiotics. Resistance to penicillin is mediated by the production of $\beta$-lactamase. Many resistance genes are acquired by plasmid mediated gene transfer and some may be transferred to the chromosome as mobile genetic elements. Methicillin resistant strains usually possess more than four genes encoding different resistant mechanism [8]. Therefore, treatment of MRSA infections is challenging and empiric treatment usually includes the use of clindamycin or vancomycin. MRSA strains that are clindamycin-susceptible but erythromycinresistant may have the in vitro inducible macrolide, lincosamide and streptogramin B (MLSB)-resistance phenotype with potential for treatment failure. Rates of inducible MLSB resistance among pediatric MRSA isolates vary widely [3].

One study in South Africa indicated antibiotic resistance of MRSA to erythromycin, tetracycline, trimethoprim/sulfamethoxazole, gentamicin and ciprofloxacin ranged between $55 \%$ and $78 \%$, while all isolates were susceptible to teicoplanin, linezolid, vancomycin and quinopristin/dalfopristin [6]. Similar study in India revealed Methicillin resistance among the Staphylococcus aureus isolates was $39.5 \%$ and resistance to all antibiotics tested among the Methicillin-resistance and Methicillin-sensitive-staphylococci was found to be $26.3 \%$ and $6.8 \%$ respectively [7].

There is a growing concern about the rapid rise in resistance of $S$. aureus to antimicrobial agents. Trends in the antibiotic susceptibility of MRSA are regularly investigated in many countries, but minimal countrywide data are available for India particularly for in the study area. Methicillin-resistance is a useful marker in selecting appropriate antimicrobial agents for treatment of infections caused by $S$. aureus changing pattern of resistance of $S$. aureus makes its periodic surveillance mandatory [7]. The present study was focused to 
determine the antimicrobial susceptibility pattern of MRSA from septicemia suspected children.

\section{Materials and Methods}

\subsection{Blood Culture Method}

The blood sample for culture was obtained from children having a clinical picture suggestive of septicemia/bacteremia before instituting antibiotic therapy. Total 300 blood specimens were collected using aseptic techniques. 2 to $5 \mathrm{ml}$ blood was drawn from each patient and was distributed in to brain heart infusion (BHI) blood culture bottles (Himedia, India). The BHI blood culture bottles were incubated at $37^{\circ} \mathrm{C}$ for aerobic and facultatively anaerobic environment for 7 days. The culture bottles were discarded if there was no growth after 7 days incubation. Any blood culture bottles flagging positive was gram stained and sub cultured on to selective and non-selective media such as Nutrient agar, Blood agar, Mannitol salt agar and Staphylococcus agar. The isolated pathogens from the blood culture were identified by standard biochemical identification methods. Yellow colonies grew on manitol salt agar and golden yellow colonies appeared on nutrient agar showing gram-positive grape-like coccoid clusters and producing DNase and coagulase were identified as $S$. aureus. The total numbers of positive culture bottle within the sets were determined.

\subsection{Antibiotic Susceptibility Testing}

The antibiotic susceptibility pattern of all the staphylococcal strains was determined by modified Kirby Bauer disc diffusion method against the following antibiotics: chloramphenicol $(30 \mu \mathrm{g})$, penicillin $(60 \mu \mathrm{g})$, Amoxicillin $(25 \mu \mathrm{g})$, oxacillin $(1 \mu \mathrm{g})$, erythromycin $(15 \mu \mathrm{g})$, gentamicin $(10 \mu \mathrm{g}), \quad$ Trimethoprim-sulfamethoxazole (1.25ug/23.75ug), ciprofloxacin $(5 \mu \mathrm{g})$, Rifampicin $(30 \mu \mathrm{g})$, erythromycin $(15 \mu \mathrm{g})$, vancomycin $(30 \mu \mathrm{g})$ and methicillin $(5 \mu \mathrm{g})$ (Himedia, India). All tests were performed on Muller-Hinton agar, and were interpreted after incubation for $24 \mathrm{~h}$ at $37^{\circ} \mathrm{C}$. The zone diameters measured around each disk were interpreted on the basis the Clinical and Laboratory Standards Institute (CLSI) [9]. S. aureus ATCC 25923 was used as a standard control strain.

\subsection{Screening Test for MRSA}

Screening test was performed in accordance to the CLSI guidelines using oxacillin agar [9]. Briefly, a bacterial suspension of $10^{6} \mathrm{cfu} / \mathrm{ml}$ was prepared from each isolate. Then a swab was dipped and streaked on the surface of a Muller-Hinton agar supplemented with $6 \mu \mathrm{g} / \mathrm{ml}$ oxacillin and $4 \% \mathrm{NaCl}$. After incubation for $24 \mathrm{hrs}$ at $35^{\circ} \mathrm{C}$, if any growth was detected, the isolate was considered MRSA.

\section{Results}

The present study identified 88 septicemia children out of 300 suspected children screened (29.33\%). The predominant isolate was Staphylococcus aureus which accounted $29.54 \%$ of the isolates. MRSA accounted $30.76 \%$ of $S$. aureus isolates (Table 1).

Table 1. Proportion of Methicillin Resistance S. aureus (MRSA) with respect to Sex in Septicaemia suspected Children in Hosur, South India (n= 26)

\begin{tabular}{|c|c|c|c|c|c|c|}
\hline & \multicolumn{2}{|c|}{ MRSA } & \multicolumn{2}{c|}{$\begin{array}{c}\text { Methicillin Sensitive } \\
\text { S. Aureus }\end{array}$} & \multicolumn{2}{c|}{ Total } \\
\hline Sex & No. & $\%$ & No. & $\%$ & No. & $\%$ \\
\hline Male & 5 & 19.2 & 10 & 38.5 & 15 & 57.7 \\
\hline Female & 3 & 11.5 & 8 & 30.8 & 11 & 42.3 \\
\hline Total & 8 & 30.7 & 18 & 69.3 & 26 & 100 \\
\hline
\end{tabular}

The antimicrobial susceptibility pattern of MRSA isolates against agents of different classes is summarized in Table 2. The drug resistance patterns of MRSA isolated from blood samples was found to be highly variable. All the MRSA strains were resistance against penicillin, rifampicin, amoxicillin, gentamicin, methicillin and all are susceptible to vancomycin and oxacillin.

Table 2. Antimicrobial Susceptibility Pattern of Methicillin Resistance Staphylococcus aureus (MRSA) from Septicaemia suspected Children in Hosur, South India

\begin{tabular}{|c|c|c|c|}
\hline \multirow{2}{*}{ Antibiotic } & \multicolumn{3}{|c|}{$\begin{array}{c}\text { Methicillin Resistance Staphylococcus aureus } \\
\text { (MRSA) }(\mathrm{n}=8)\end{array}$} \\
\cline { 2 - 4 } & $\mathrm{S}[\mathrm{n}(\%)]$ & $\mathrm{I}[\mathrm{n}(\%)]$ & $\mathrm{R}[\mathrm{n}(\%)]$ \\
\hline Am & $\mathrm{ND}$ & $\mathrm{ND}$ & $8(100)$ \\
\hline ERT & $2(25)$ & $3(37.5)$ & $3(37.5)$ \\
\hline SXT & $3(37.5)$ & $\mathrm{ND}$ & $5(62.5)$ \\
\hline CIP & $5(62.5)$ & $2(25.0)$ & $1(12.5)$ \\
\hline A & ND & ND & $8(100)$ \\
\hline G & ND & ND & $8(100)$ \\
\hline C & $6(75.0)$ & ND & $2(25.0)$ \\
\hline Ox & $8(100)$ & ND & ND \\
\hline P & ND & ND & $8(100)$ \\
\hline R & ND & ND & $8(100)$ \\
\hline Va & $6(75.0)$ & $2(25)$ & ND \\
\hline M & ND & ND & $8(100)$ \\
\hline
\end{tabular}

MRSA = Methicillin Resistance Staphylococcus aureus, ND= Not detected, $\mathrm{AM}=$ Amoxacillin, $\mathrm{A}=$ Ampicillin, $\mathrm{G}=$ Gentamycin, $\mathrm{Ox}=$ Oxacillin, $\mathrm{P}=$ Penicillin $-\mathrm{G}, \mathrm{R}=$ Rifampicin, $\mathrm{Va}=$ Vancomycin, $\mathrm{M}=$ Methicillin, $\mathrm{C}=$ Chloramphenicol, ERT $=$ Erythromycin, $\mathrm{SXT}=$

Trimethoprim sulfamethoxazole, $\mathrm{CIP}=$ Ciprofloxacin, $\mathrm{S}=$ Susceptible, I= Intermediate, $\mathrm{R}=$ Resistance

\section{Discussion}

The septicemia infection is prevalent children in India, especially the age group between 1-5 years. The prevalence rate of MRSA infection in this study was found to be $30.7 \%$ which is corroborate with studies conducted in Nepal [10] and India [11,12,13]. There is a growing concern about the rapid rise in resistance of $S$. aureus to antimicrobial agents [14]. In this study, all clinical MRSA strains (100\%) were resistant to penicillin, rifampicin, ampicillin, gentamicin, and amoxacillin. A similar result was noted for gentamicin and penicillin in South India $[15,16]$ and Tridad and Tobago (Southern Caribbean) [17].

To our knowledge, the present study provides the most comprehensive description to the epidemiology and burden of MRSA infection among Septicemia Suspected children in Hosur, South India. We found that more than half of MRSA isolates were susceptible to oxacillin $(100 \%)$, vancomycin $(75 \%)$, chloramphenicol $(75 \%)$, and 
ciprofloxacin (62.5\%). A similar result was reported to ciprofloxacin and vancomycin from South Africa [6], Tridad and Tobago [17], and Pakistan [18]. During the study period, we identified a stable increase in both the overall incidence of $S$. aureus infection and the incidence of MRSA infection

\section{Conclusion}

The present study identified a recent increase in MRSA infection among septicemia suspected children. The regular monitoring antibiotic susceptibility pattern of MRSA and selection of a definite antimicrobial agent may be helpful for reducing the incidence of MRSA infections in septicemia children. These measures need to be implemented consistently in order to reduce the burden of MRSA infection in the hospital environment.

\section{Acknowledgements}

The authors would like to thank to SBS Hospital Pvt Ltd, Hosur, India.

\section{Statement of Competing Interests}

The authors declare no potential conflicts of interest.

\section{References}

[1] Gonzalez BE, Martinez-Aguilar G, Hulten KG, Hammerman WA, Coss-Bu J, Avalos-Mishaan A et al. Severe Staphylococcal Sepsis in Adolescents in the Era of Community-Acquired MethicillinResistant Staphylococcus aureus. Pediatrics. 2005; 115(3): 642-8.

[2] Al-Baidani AH, El-Shouny WH, Shawa TM. Antibiotic Suseptiblity Pattern of Methicillin Resistance Staphylococcus aureus in Three Hospitals at Hodeidah City, Yemen. Global J. Pharmacol. 2011; 5(2):106-111.

[3] Ochoa TJ, Mohr J, Wanger A, Murphy JR, Heresi GP. Communityassociated Methicillin-resistant Staphylococcus aureus in Pediatric Patients. Emerging Infectious Diseases. 2005; 11 (6):966-968.

[4] Huang YC, Chao AS, Chang SD, Chen YJ, Peng MT, Sung JH et al. Association of Staphylococcus aureus colonization in parturient mothers and their babies. Pediatr Infect Dis J. 2009; 28(8):742-4.

[5] Groundmann H, Sousa M, Boyce J, Tiemesma E. Emergence and resurgences of MRSA as a public health threat. Lancet. 2006; 368(9538):874-85.

[6] Marais E, Aithma N, Perovic O, Oosthuysen WF, Musenge E, Dusé AG. Antimicrobial susceptibility of methicillin-resistant Staphylococcus aureus isolates from South Africa. S Afr Med J. 2009; 99(3):170-3.

[7] David MZ, Daum RS. Community-Associated MethicillinResistant Staphylococcus aureus: Epidemiology and Clinical Consequences of an Emerging Epidemic. Clinical Microbiology Reviews. 2010; 23(3):616-687.

[8] Nwankwo EOK, Sale A, Magagi A, Gabriel I. Methicillin Resistant S. aureus (MRSA) And Their Antibiotic Sensitivity Pattern In Kano, Nigeria. Afr. J. Cln. Exper. Microbiol. 11(1): 129-136.

[9] Wikler MA, Cockerill FR, Criag WA, Dudley MA, Eliospoulos MA, Hecht DW et al. Performance Standards for Antimicrobial Sensitvity Testing: Seventheenth Informational Supplement. CLSI. 2007; 26(3):1-177.

[10] Kumari N, Mohapatra TM, Sing YI. Prevalence of methicillin resistant Staphylococcus aureus (MRSA) in tertiary -Care hospital in eastern Nepal. J. Nepal Med. Assoc. 2008: 47 (170): 53-56.

[11] Mehta AP,, Rodrigues C, Sheth K, Jani S, Hakimiyan A, Fazalbhoy N. Control of methicillin resistant Staphylococcus aureus in tertiary care center: a five year study. Indian J. Med. Microbiol. 1998: 16: 31-34.

[12] Udaya Shankar C, Harish BN, Umesh Kumar PM, Navaneeth BV. Prevalence of methicillin resistant Staphylococcus aureus in JIPMER hospital. Indian J Med Microbiol. 1997; 15:137-138.

[13] S Anupurba, MR Sen, G Nath, BM Sharma, AK Gulati, TM Mohapatra. Prevalence of methicillin resistant staphylococcus aureus in a tertiary referral hospital in eastern Uttar Pradesh. Indian J Med Microbiol. 2003: 21(1): 49-51.

[14] Mulla S, Patel M, Shah L, Vaghela G. Study of antibiotic sensitivity pattern of methicillin-resistant Staphylococcus aureus. Indian J Critical Care Medicine. 2007; 11(2): 99-101.

[15] Saravanan M, Nanda A. Incidence of methicillin resistant Staphylococcus aureus (MRSA) from septicemia suspected children. Indian J.Sci.Technol. 2009; 2(12):36-39.

[16] Rajaduraipandi K, Mani Kr, Panneerselvam K, Mani M, Bhaskar M, Manikandan P. Prevalence And Antimicrobial Susceptibility Pattern Of Methicillin Resistant Staphylococcus aureus: A Multicentre Study. Indian J. Med. Microbiol. 2006; 24(1):34-8.

[17] Akpaka PE, Kissoon S, Swanston WH, Monteil M. Prevalence and antimicrobial susceptibility pattern of methicillin resistant Staphylococcus aureus isolates from Trinidad \& Tobago. Ann Clin Microbiol Antimicrob. 2006, 5:16.

[18] Kaleem F, Usman J, Hassan A, Omair M, Khalid A, Uddin R . Sensitivity pattern of methicillin resistant Staphylococcus aureus isolatedfrom patients admitted in a tertiary care hospital of Pakistan. IJM. 2010: 2(3):141-143. 